\title{
ЛОГИСТИЧЕСКАЯ ИНТЕГРАЦИЯ: НОВЫЕ УСЛОВИЯ И ТЕХНОЛОГИИ
}

\author{
С.Ф. Куган ${ }^{*}$
}

Проанализирована история развития логистики и предложена классификация этапов, основанная на критериях функционального содержания и интенсивности материальных потоков во времени. Сформулированы характеристики каждого этапа логистики. Отражены перспективные направления развития логистики в период цифровизации.

Ключевые слова: цифровая логистика, цифровые технологии, цифровые транспортные системы, этапы развития логистики.

JEL-классификация: O10, O30.

DOI: $10.46782 / 1818-4510-2021-3-138-149$

Материал поступил 28.04.2021 2.

Современная экономика представляет собой гибрид постиндустриальной и цифровой экономики. Имеющий место стремительный переход к цифровой экономике обусловлен активным развитием и широким распространением информационнокоммуникационных технологий, повлекших за собой ускорение роста наукоемких отраслей производства, увеличение объемов информационных потоков и их трансформацию в контексте существующих потребностей бизнеса. Впервые понятие «цифровая экономика» в научной интерпретации использовано в 1995 г. американским ученым Н. Негропонте (Массачусетский университет $)^{1}$. Именно он, объясняя коллегам положения «электронной экономики» и перспективы интенсивного развития информационно-коммуникационных технологий, употребил термин «digital economy». Позднее этот термин был раскрыт в работе Д. Тапскотта ${ }^{2}$. «Цифровая экономика» в трактовке Д. Тапскотта представляет собой технологически сложную цифровую систему, состоящую из взаимосвязанных и взаимодействующих элементов, опосредован-

\footnotetext{
${ }^{1}$ Цифровая экономика. URL: https://ru.wikipedia.org/ wiki/

2 Tapscott D. 1994. The Digital Economy: Promise and Peril in the Age of Networked Intelligence. McGraw Hill.
}

ных технологиями. В качестве элементов, образующих единое целое, ученый рассматривал личность, коллектив, предприятия, осуществляющие взаимодействие посредством цифровых сетей. Постепенно это понятие распространилось на многие сферы человеческой деятельности и стало общепринятым.

Эпоха цифровой экономики породила не только новые виды бизнеса, но и новые способы взаимодействия. Значительная доля компаний, которые не смогли организовать свой бизнес в соответствии с требованиями цифровой экономики, столкнулись с такими негативными явлениями, как снижение объемов продаж, потеря части позиций на рынке, банкротство. В настоящее время не существует четкого перечня, очерчивающего конкретный круг отраслей производства, которые можно было бы включить в область цифровой экономики. Подобное затруднение связано с тем, что современные технологии отличаются высокой динамичностью и исследователям сложно подвести теоретический базис под быстроизменяющиеся реалии.

Цифровая экономика представлена не только онлайн-процессами, рекламой в сети Интернет, электронными валютами и банковскими трансакциями. Сегодня внедре-

* Куган Светлана Федоровна (sfkugan@mail.ru), кандидат экономических наук, доцент, Брестский государственный технический университет (г. Брест, Беларусь). https://orcid.org/0000-0002-7307-4268 
ние цифровых технологий в бизнес способствует уменьшению зависимости от посредников, минимизации издержек при возмещении расходов. Кроме того, мы наблюдаем преобразование в цифровой вид практически всех аспектов делового общения. Наиболее ярко эти преобразования можно увидеть, исследую историю развития логистики.

\section{Классификащия әтапов развития логистики}

Логистика как наука и методология управления потоками формировалась на протяжении длительного периода времени. Данному процессу предшествовала большая социальная практика, в первую очередь в военной сфере. Становление, развитие и смена взглядов на сущность и содержание логистики прошли достаточно большой путь от первых сделок по обмену продуктов до современных международных договоров купли-продажи. Изучение основных законов о перемещении материальных и других ценностей фактически связало логистику со всеми сферами человеческой деятельности. Опираясь на мнения ряда исследователей (Бродецкий, 2006; Гордон, Карнаухов, 1998) и учитывая примитивность обменных операций первобытных племен, нами предложена следующая классификация этапов развития логистики, основанная на критериях интенсивности материальных потоков во времени и функциональном содержании определенного временного интервала.

1. Ранняя логистика (IV-II вв. до н.э.$\mathrm{IX}-\mathrm{XV}$ вв. н.э.) - частичное использование элементов логистики при перемещении материальных ценностей, главным образом в торговле и снабжении войск. В Древней Греции (Платон, Аристотель, Ксенофонт) и Древнем Риме (Катон, Варрон, Колумелла, Плиний) мыслители представляли торговые операции как простые действия, связанные с обменом, поэтому использование элементов логистики осуществлялось в основном в хозяйственной практике ${ }^{3}$. Слабое развитие торговых отношений объясняется господством натурального хозяйства. В средние века (Be-

3 Всемирная история экономической мысли. 1987. Москва: Мысль. ликий шелковый путь, Византийская империя) отдельные элементы логистики используются в торговле, распределении продуктов питания и обеспечении войск материальными ресурсами. В Средние века активно развивались морские и речные торговые пути. Купцы предпочитали речные дороги сухопутным, как более дешевые и безопасные. Развитие больших сухопутных дорог начиналось в середине XIII в. и способствовало образованию множества небольших рынков, а в дальнейшем определило формирование крупных торговых центров в Руане, Реймсе, Орлеане, Тулузе и др. ${ }^{4}$ Средние века для Китая были тяжелым периодом, связанным с нашествием кочевых племен. Именно в это время на Шелковом пути активизируется обмен духовными и материальными ценностями, важнейшими результатами которого являются буддийское завоевание Китая и проникновение культуры шелководства и шелкоткачества на Запад 5 . В период правления династии Тан (618-907 гг. н.э.) активно развиваются торговля и производство. Изобретение компаса способствовало развитию мореходства. Наступившая для Европы эра открытий связана с началом активных торговых отношений с Китаем.

2. Торгово-ремесленная логистика характеризуется развитием промышленности и укрупнением торговых операций, в результате чего логистика выполняет функции интеграции и координации с элементами территориально-продуктового регулирования (конец XV - начало XIX в.). Вместе с торговлей появляется и разрастается промышленность, особенно горная. Разрозненность европейских государств, таможенные барьеры, отсутствие единой политики вредили интересам внутренней и внешней торговли. Торговля и промышленность в основном сосредотачивались в тех государствах, в которых можно было рассчитывать на стойкий и значительный внутренний рынок. Дальнейшее укрупнение торговых операций определило межгосударственное взаимодействие на Европейском континенте, в результате которого в 1834 г. был со-

${ }^{4}$ Кулишер И.М. 2002. Основные вопросы международной торговой политики. Москва: Социум. 480 с.

5 Лубо-Лесниченко Е.И. 1994. Китай на Шелковом пути (Шелк и внешние связи древнего и раннесредневекового Китая). Москва: Восточная литература. 326 с. 
здан таможенный союз Zollverein, объединивший большинство немецких государств и территорию Пруссии. Им были установлены общая система мер и весов, монетная система. Но самым главным достижением союза можно считать отмену таможенных преград между участниками и формирование общего дохода из взимаемых пошлин. В этот период предпринимаются первые попытки осмысления практического опыта логистики. Первым исследователем, представившим логистику как науку, является французский военный писатель Г. Жомини (1837 г. - книга «Очерки военного искусства»), рассматривавший ее не просто как процесс материального перемещения в войсках, а как совокупность функций управления: планирование, организация и снабжение 6 .

3. Производственная логистика (середина XIX - середина XX в.) отмечена распространением накопленных в военном деле знаний логистов на все отрасли экономики, что нашло свое применение в процессах и операциях, связанных с пространственно-временным перемещением товарно-материальных ресурсов на производстве, при транспортировке и складировании. По мнению зарубежных специалистов (Гордон, Карнаухов, 1998; Иванов, 2006; Christopher, 1998), точечное внедрение элементов логистики во всех отраслях экономики того времени связано с небольшими размерами материальных потоков и связанных с ними общих затрат. Логистика обслуживает интересы материального производства в условиях формирования классического рынка продавца, и ее деятельность ориентирована на снижение суммарных операционных затрат. В это же время свое применение нашла концепция общих затрат, основные принципы которой были положены в основу формирования методологии принятия логистических решений (Зверев, Авдей, 2012). Сущность данной концепции выражалась в перераспределении издержек с целью достижения существенного сокращения общего уровня затрат в цепи поставок товаров от производителя к потребителю. Дальнейшее развитие промышленности и, как следствие, уве-

\footnotetext{
${ }_{6}$ Жомини Г. 1939. Очерки военного искусства. Москва: Воениздат. Т. 2. 206 с.
}

личение материальных и товарных потоков определили необходимость появления в этот период первых организаций, занимающихся вопросами и проблемами логистики. Одной из таких организаций стала Национальная ассоциация проблем управления закупками (1915 г.), преобразованная затем в Национальную ассоциацию агентов снабжения (1967 г.).

Активное развитие экономики в начале XX в. было приостановлено военными действиями, охватившими большинство экономически развитых на тот период государств. Принципы логистики нашли свое применение при ведении военных действий. Целевая функция логистики в военный период состояла в организации процесса срочной эвакуации производственных предприятий с прифронтовой зоны. Сохранение технологической целостности производства, а также комплектности оборудования явилось необходимым условием обеспечения потребностей фронта и тыла. Это было обусловлено переводом «всей транспортной системы на рельсы военного времени», вследствие чего осуществлялся поиск дополнительных резервов и усиливался «контроль над правильностью погрузки и заполнения емкости вагонов» (Батюк, Гадимова, 2015). Практическая значимость разработанных логистических подходов по координации работы тыла и транспорта, обеспечения снабжения и перемещения огромных воинских контингентов доказана советскими военными специалистами в годы Второй мировой войны. Опыт логистического взаимодействия был также успешно использован во время открытия второго фронта американской армией, применившей принципы единого управления и координации снабжения, складирования и транспортировки. Навыки, полученные в годы войны, и дальнейший послевоенный экономический рост предопределили практическое и научное развитие логистики. В 1949 г. создан Совет Европы, а уже в 1951 г. учреждено Европейское объединение для упорядочения потоков по перемещению угля и стали (Зверев, Авдей, 2012).

4. Клиентоориентированная логистика, сформированная развивающимся рынком покупателя (середина XX - начало XXI в.). 
В научных исследованиях ${ }^{7}$ описывается переход мировой экономики от рынка производителя к рынку потребителя, ставший ключевым фактором, объясняющим распространение логистики в бизнесе. В начале второй половины XX в. в США создается Национальный совет по менеджменту физического распределения, в дальнейшем преобразованный в Совет логистического менеджмента. В это же время открывается Европейский центр по логистике (Швейцария). Практическое и теоретическое развитие логистики было обусловлено следующими факторами: ростом товарных и производственных запасов, а также транспортных расходов; увеличением транспортных тарифов; появлением и быстрым распространением концепции маркетинга; развитием теории военной логистики (Бродецкий, 2006; Лебедев, 2007).

Для этого периода характерны постепенное расширение сферы применения логистики во многих отраслях экономики и частое использование логистического подхода в сфере обращения. Объектом логистики становилась любая деятельность, в которой последовательность процессов и их результатов имела временную или пространственную альтернативу (Гарнов, Киреева, 2018). Как правило, это распространялось не только на материальные, но и сопровождающие их потоковые процессы.

Параллельно с развитием логистики происходит углубление экономической интеграции:

в 1957 г. создано Европейское экономическое сообщество (ЕЭС);

в 1968 г. страны ЕЭС ввели Единый таможенный тариф для третьих стран, отменив их для стран-участниц;

в 1992 г. создан Европейский союз (EC).

Логистическая методология и ее инструментарий все больше отрываются от военной сферы и смещаются в сторону экономики, что определялось возросшими требованиями конкуренции на товарном рынке, усложнением рыночной конъюнктуры, стремлением хозяйственников быстрее

7 Лукинский В.С., Лукинский В.В., Пластуняк И.А., Плетнева Н.Г. 2005. Транспортировка в логистике: учебное пособие. Санкт-Петербург: СПбГИУЭ. 139 с. адаптироваться к быстро меняющимся обстоятельствам. Западные специалисты ${ }^{8}$ (Christopher, 1998) отмечали, что для данного периода характерна интеграция экономических процессов в разных сферах: общий товарный рынок, создание Шенгенской зоны, ввод в обращение единой валюты. Все эти процессы привели к качественным изменениям рынка покупателей, сформировав единую политику торговли, что, в свою очередь, увеличило роль сервиса поставок в стратегиях компаний. В регулировании бизнес-процессов западных компаний все чаще использовался логистический подход, основанный на теории управления физическим распределением продукции (physical distribution management). Реализация данного подхода позволяла регулировать потоки готовой продукции при ее прохождении через длинный ряд звеньев сети распределения. В этот период продолжается развитие транснациональных компаний, что приводит к необходимости создания специальных служб и отделов, отвечающих за логистические операции. Постепенно большинство компаний в своей практической деятельности используют функциональные возможности и законы логистики. К основным решаемым задачам того периода можно отнести: объединение обособленно существующих потоков в производстве, хранении и транспортировании в единую систему управления и получение экономического эффекта через внедрение отдельных функций логистики в производственную деятельность предприятий.

В это же время концепция логистики рассматривается как интегральный инструмент управления и представляет собой «менеджмент всех видов деятельности, которые способствуют движению и координации спроса и предложения на товары в определенном месте и в заданное время» ${ }^{9}$. На Первом европейском конгрессе по логистике (Берлин, март 1974 г.) специалисты определили логистику как науку, изучающую системное планирование и контроль товарных, пассажирских и сопутству-

${ }^{8}$ Джонсон Дж.С., Вуд Д.Ф., Вордлоу Д.Л., Мэрфи П.Р. 2004. Современная логистика. Москва: Вильямс. 615 с.

9 Таничев А.В. 2003. Логистика. СПб: Издательский дом «Нева». С. 19. 
ющих им потоков, а также управление ими ${ }^{10}$. Тогда же были сформулированы фундаментальные принципы логистики и отмечена «ее способность не только регулировать потоковые процессы, но и обеспечивать» оптимальное управление этими «процессами с целью выявления и реализации скрытых резервов, обеспечивающих дополнительные доходы и возможности субъектов хозяйствования» (Гарнов, Киреева, 2018. С. 36). Несмотря на заинтересованность ученых и специалистов в новом экономическом направлении, позволяющем повысить прибыль, роль логистики в части снижения общих затрат для руководства большинства компаний еще не очевидна. В 1975 г. за теорию оптимального распределения ресурсов двое ученых, Л. Канторович и Т. Купманс, получили Нобелевскую премию по экономике. В конце 1970-х годов в Ленинграде разработана логистическая технология, описывающая работу транспорта различных видов по методу транспортного узла, где осуществлялось их взаимодействие. Эта технология была использована западными специалистами при создании единой Европейской транспортной системы стран ЕС.

Примером решения проблем логистики на государственном уровне стали разработка и внедрение в бывшей ГДР в конце 80-х годов ХХ в. системы единого комплексного управления транспортом страны (ЛСЕКУТ), в основу которой положена оптимизация грузовых перевозок. Этот период отмечен также активным практическим применением разработанных для микро- и мезоуровня транспортно-логистических систем. Использование принципов системы оперативного планирования перевозок (НИИ автомобильного транспорта, г. Москва) позволяло доставлять грузы в заданный срок и сокращать запасы у потребителей. Успешное внедрение на железных дорогах межотраслевой системы «Ритм» (ВНИИ железнодорожного транспорта, г. Москва) сыграло определенную роль в снижении объемов запасов сырья и топлива у потребителей (Магомедов, 2014).

${ }_{10}$ Миротин Л.Б., Ташбаев Ы.Э. 2002. Логистика для предпринимателя: учебное пособие. Москва: ИНФРА-М. 251 с.
Другими словами, клиентоориентированный период отмечается активным становлением логистики как науки, а практическая ее составляющая приобретает многофункциональную форму по продвижению материальных потоков с широким привлечением современных информационных систем. Методологию физического распределения («physical distribution») сменяет комплексный логистический подход, основанный на концепции интегрированной логистики, представляющей собой совокупность взаимосвязанных операций: снабжение производства требуемым сырьем и материалами (логистика снабжения); производство готовой продукции (логистика производства); доставка изделий и товаров конечному потребителю (логистика распределения). Постепенно логистика становится одним из главных факторов национального успеха, особенно в части создания конкурентных преимуществ. Являясь важным направлением развития для крупных, средних и малых предприятий, логистика занимается вопросами организации циклических потоков и движением широкой номенклатуры товаров на основе оптимизации затрат и высоком качестве предлагаемых услуг.

Развитие логистики этого периода характеризуется оптимизацией хозяйственного управления, стремительным развитием концепции управления цепями поставок (SCM-концепция) в индустриально развитых странах. Дальнейшее расширение торговых отношений позволило реализовать большинство масштабных задач по осуществлению продвижения товарно-материальных, информационных и финансовых потоков через интеграционное пространство в виде создания новых экономических союзов:

1989 г., Азиатско-Тихоокеанское экономическое сотрудничество (Asia-Pacific Economic Cooperation, APEC) - сотрудничество 21 государства;

1991 г., MEРКОСУР (Mercado Comun del Sur, MERCOSUR) - экономический союз Аргентины, Парагвая, Уругвая и Бразилии (Асунсьонский договор);

1992 г., НАФТА (North American Free Trade Agreement, NAFT) - устранение барьеров между странами-участницами 
(США, Мексика, Канада) посредством соглашений о свободной торговле.

Создание подобных союзов не только расширяло возможности торговли, но и упрощало реализацию таможенных операций между странами-участницами. Интеграция на постсоветском пространстве представлена следующими процессами:

в 1991 г. образовано Содружество Независимых Государств (СНГ). Спустя некоторое время три страны - Россия, Казахстан и Беларусь - предпринимают определенные попытки к созданию Таможенного союза (1995 г.);

в 1999 г. заключен Договор о Таможенном союзе (ТC) и Едином экономическом пространстве между Беларусью, Россией, Казахстаном, Кыргызстаном и Таджикистаном (позднее и с Узбекистаном);

в 2000 г. подписан Договор об учреждении Евразийского экономического сообщества (ЕврАзЭС);

в 2001 г. создана Шайнхайская организация сотрудничества (ШОС), в которую сегодня входят Индия, Казахстан, Кыргызстан, КНР, Пакистан, Россия, Таджикистан, Узбекистан.

Международные программы и проекты способствовали активному применению инструментов логистики. С этого момента логистика, в особенности международная, рассматривалась как комплекс, реализующий задачи по размещению производства и центров дистрибуции, по выбору видов транспортного перемещения, методов управления запасами, по проектированию подходящих под ситуацию коммуникационных и информационных систем.

5. Сервисно-модульная логистика, отличающаяся не только многофункциональностью, но и высокой адаптивностью к изменениям внешней среды и глобальным характером присутствия на основе современных технико-технологических решений с применением эффективных информационно-коммуникационных систем управления (начало XXI в. - наст. время). В этот период появилась необходимость в формировании первых логистических интеграционных механизмов между предприятиями - производителями товаров и предприятиями розничной торговли. Реализация этих ме- ханизмов позволила решить вопросы снижения закупочной цены товара с одновременным увеличением объема закупок и выходом на мировые рынки. Основные вопросы, решаемые логистикой, относились к оптимизации управления в части организации взаимодействия материальных, финансовых и информационных потоков при реализации задач стратегического, тактического и оперативного планирования ${ }^{11}$ (Ковалев, Королева, Дутина, 2017). Организация международных перемещений ресурсов становится важным направлением экономики для развитых стран, а активное использование информационно-коммуникационных технологий (ИКТ) позволяло осуществлять мониторинг всех фаз движения товара. Кроме того, в этот процесс активно включаются страны с развивающейся и переходной экономикой. Характерная для этого периода оптимизация в сфере обращения определила недостаточность перестройки отдельных составляющих деятельности компаний, так как рост расходов в одном из видов деятельности оказывал влияние на все процессы сферы сопряжения, приводя к их удорожанию. Это позволило рассматривать влияние логистики на всю совокупность бизнес-процессов и прогнозировать дальнейшее их развитие.

В 2006 г. стремление к сотрудничеству пяти стран - России, Индии, Южно-Африканской Республики, Китая и Бразилии выливается в создание организации с аббревиатурой БРИКС. В тот же период Беларусь, Казахстан и Россия в рамках ЕврАзЭС договариваются о создании Таможенного союза, и в октябре 2007 г. заключается ряд соответствующих договоров и соглашений. С 1 января 2012 г. на территории трех стран - участниц Таможенного союза ЕврАзЭС начинает действовать Единое экономическое пространство (ЕЭП). Его отличительной чертой становится согласование налоговой, денежно-кредитной, валютно-финансовой и таможенной политики (Родкина, Комарова, 2017. С. 31). В 2014-2015 г. создается Евразийский экономический союз

11 Грейзс Г.М. 2017. Информационно-аналитическое обеспечение системы управления логистическими потоковыми процессами промышленного предприятия: дис. ... д-ра экон. наук: 08.00.05. 
(ЕАЭС) с присоединением Кыргызстана (декабрь 2014 г.) и Армении (январь 2015 г.).

Постепенно логистика становится надежным инструментом снижения рисков и повышения конкурентоспособности предприятий, регионов, государств. Переориентация рынка формирует понимание, что процесс доставки товара до конечного потребителя становится одним из важнейших в логистике или новой его форме - цепи поставок. Подобное позиционирование позволило разработать и успешно применять сквозное управление по всей логистической цепи, сформировалась новая идеология - управление цепями поставок (Антюшеня, 2016. С. 22).

Проведенная классификация этапов развития логистики подтверждает научную гипотезу, что эволюция логистики еще не завершена. В настоящее время происходит постоянное совершенствование интеграционных процессов, которые на фоне развития международных логистических связей переводят логистику в приоритетное направление экономической политики. Логистика на разных этапах своего эволюционирования предлагала действенные инструменты осуществления бизнес-процессов, становясь «важным стратегическим инструментом в конкурентной борьбе» для многих предприятий и организаций ${ }^{12}$. Цифровые технологии, активно используемые бизнесом, в современном мире представляют собой не точечные, т. е. разовые решения, а интегрированные технологии, объединяющие разнообразные бизнес-процессы, реализуемые в едином информационном пространстве. Современный этап развития мировой экономики предусматривает внедрение интегрированных технологий, что значительно расширяет территории взаимодействия участников международных логистических систем. Данные технологии включают планирование и управление запасами, использование инновационных решений для реализации логистических бизнес-процессов, межорганизационную и международную интеграцию, создание единого информационного пространства, контроллинг и аутсортинг (Дыбская, Сергеев, 2018). Взаимосвязанность

12 Альбеков А.У., Митько О.А., Федько В.П. 2001. Логистика коммериии: учебное пособие. Ростов-на-Дону: Феникс. С. $17-18$. интересов потребителя и бизнеса связана с тем, что подобное взаимодействие затрагивает интересы всех участников логистической системы любого уровня и позволяет находить инновационные решения для достижения поставленных целей. Исследование генезиса логистики позволило проанализировать основные этапы ее развития и сделать вывод, что они протекали весьма интенсивно, при этом сама трансформация логистических идей осуществлялась недостаточно равномерно.

Это связано с пересечением интересов специалистов различных направлений: маркетологов, финансистов, менеджеров и логистов. Данная тенденция сохранилась и до настоящего момента. Именно сегодня интенсивность внедрения логистики столь высока, что часто наблюдается картина, когда современные производственные и торговые компании не успевают оценить результаты внедрения логистических подходов и, соответственно, не успевают на качественном уровне освоить действенные логистические инструменты, направленные на долгосрочное развитие их бизнеса. Активное развитие цифровых технологий позволяет предположить, что следующим этапом генезиса логистики станет цифровая логистика, которая привнесет в экономику не только новые рыночные модели, но и новые формы и методы оказания логистических услуг (рис. 1).

Масштабная трансформация, обусловленная появлением новых рыночных моделей, изменивших механизмы создания цепочек ценностей для субъектов транспортного и товарного рынков, национальных

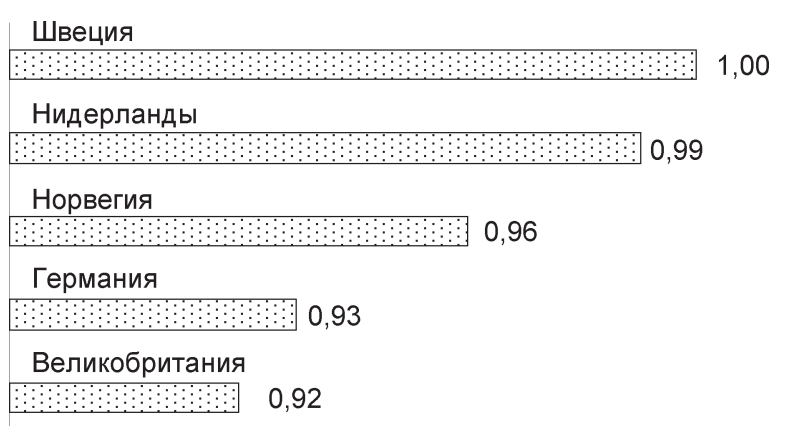

Рис. 1. Рейтинг стран по уровню принятия новых технологий населением и гражданским обществом (первые пять стран)

Источник. KPMG International, 2019 г. 
и международных цепочек создания стоимости, вывела на лидирующие позиции динамические модели и «умные» технологии организации производства и управления производственно-экономическими процессами на транспорте, объединяющие все виды транспорта в единой «бесшовной» цифровой технологии. Информационное пространство, являющееся фундаментом цифровой экономики, на основе использования электронного документооборота сделало возможными реализацию цифровых коридоров и применение технологий больших данных (Big Data). Одним из положительных примеров реализации цифрового коридора стал проект, позволивший осуществить транзитную перевозку продовольственных грузов в крытых вагонах в цифровом формате, в рамках концепции создания экосистемы цифровых транспортных коридоров ЕАЭС. Этот проект осуществлен благодаря сотрудничеству по организации перевозок импортных грузов в ITформате через электронную торговую площадку российской компании ООО «Цифровая логистика» и гомельского филиала РУП «Белтаможсервис» ${ }^{13}$. Кроме того, именно цифровые технологии сделали возможной реализацию проектов, направленных на создание транспортных средств, способных функционировать при минимальном участии человека.

\section{История развития беспилотных транспортных средств}

Проекты в области беспилотного транспорта - новое направление в логистике. Современные цифровые технологии позволяют не только создавать беспилотные транспортные средства, но и использовать их в интересах бизнеса. Необходимо отметить тот факт, что цифровая логистика - это взаимодействие клиентов и логистических операторов через цифровую платформу, «что существенно сокращает для клиента стоимость перевозок, ускоряя ее реализацию» (Королева, 2019). Расширяется рынок автоматически управляемых (беспилотных) грузовых автомобилей. Согласно прогнозу компании

${ }^{13}$ URL: https://declarant.by/ru/news/beltamozhservicetogether-with-the-russian-company-digital-logistics-organizedthe-first-export-ship/
McKinsey, в 2025 г. каждый третий европейский грузовой автомобиль будет оснащен системой автоматического управления ${ }^{14}$. Активные разработки в этом направлении выявили положительные (снижение транспортных затрат, уровня аварийных ситуаций на дорогах) и отрицательные (определенные сложности работы в городском пространстве, в сложных погодных условиях) эффекты, что позволяет говорить и о сложности исследований, и о высокой заинтересованности бизнеса в них. И если раньше исследования в сфере беспилотных технологий были единичными и больше походили на реализацию чисто научного интереса, то сегодня мы наблюдаем заинтересованность ряда государств в стимулировании и развитии подобных проектов. Активно развивается и индустрия общественного транспорта. Большинство аналитиков прогнозирует рост этого рынка и увеличение продаж беспилотных грузовиков и автобусов в ближайшей пятилетке более чем в 400 раз. Планируемый доход в 2022 г. составит порядка 35 млрд долл. США. Количественное увеличение рынка прогнозируется в 500 раз, что составит 188 тыс. ед. техники (рис. 2).

На наш взгляд, наибольший интерес представляют следующие исследования.

В 2018 г. реализован совместный проект по перевозке грузов на беспилотных грузовиках логистическим оператором DB

${ }^{14}$ URL: https://adindex.ru/publication/opinion/ internet/2013/06/7/99583.phtml

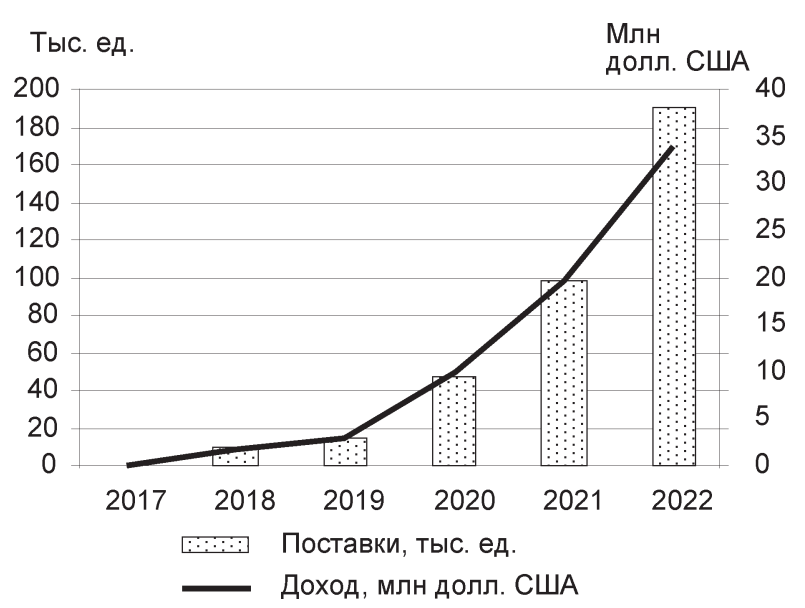

Рис. 2. Поставки беспилотных автобусов и грузовых автомобилей на мировых рынках

Примечание. 2021 г., 2022 г. - прогноз.

Источник. URL: https://www.tadviser.ru/index.php 
Schenker, автопроизводителем MAN Truck \& Bus и университетом прикладных наук им. Фрезениуса.

В 2019 г. заявили о первых регулярных перевозках на дорогах общего пользования логистический оператор DB Schenker и шведский стартап Einride;

успешно прошли испытания автоматизированных грузовиков с технологией SAE Level 4 на дорогах общего пользования концерном Daimler (производитель автомобилей под маркой Mercedes-Benz) и компанией Torc Robotics;

«КамАЗ», при участии компании «ВИСТ Групп» и казахстанского Назарбаев Университета, представил свой первый коммерческий беспилотный автомобиль (перевозка грузов по территории промышленных объектов);

компания «Нyundai» разработала систему для передвижения беспилотных фур в автоколонне;

в штате Калифорния принят законопроект, разрешающий выводить беспилотные легковые грузовики и грузовые фургоны на дороги общего пользования.

В 2020 г. реализован совместный проект «Газпром нефти» и группы компаний «КамАЗ» по испытанию работы беспилотных грузовых автомобилей в сложных природно-климатических условиях Заполярья;

на заводе «КамАЗ» в тестовом режиме прошел испытание беспилотный робот-тягач, который передвигается по заданным маршрутам, помогая рабочим собирать двигатели; создан модифицированный тягач Freightliner Cascadia благодаря сотрудничеству Waymo (дочерняя компания Google) и Daimler;

компания «Эвокарго» представила беспилотный малотоннажный грузовик EVO-1, поддерживающий технологии взаимодействия с подключенной инфраструктурой «умной дороги» (V2X).

В 2021 г. компании «Эвокарго» и «Первая экспедиционная компания» запустили первый в России коммерческий проект по реализации сервиса транспортировки грузов беспилотными транспортными средствами EVO-1 на закрытой территории. Перевозки организованы на территории логистического центра ПЭК Бутово; в Республике Беларусь беспилотный автомобиль предложила изготавливать компания «БелАЗ». Производитель показал на одной из специализированных выставок самосвал с автономной работой через GPS/ ГЛОНАСС. Оператор может управлять одновременно 4-5 машинами.

Беспилотный транспорт способен изменить экономику как самих логистических и транспортных компаний, так и целых отраслей. В качестве открытых остаются вопросы экономического характера - стоимость беспилотных автомобилей в настоящее время дороже обычных грузовиков примерно на $20 \%$. Однако, в перспективе, их стоимость может снизиться за счет оригинальных инженерных решений.

\section{Беспилотные летательные аппараты}

Еще одним перспективным направлением является использование беспилотных летательных аппаратов - дронов. Имея определенные преимущества, дроны до сих пор не нашли широкого применения в логистике. Это связано с рядом проблемных вопросов, которые влияют на масштабность их использования (малая мощность энергоносителей, ограничения по техническим показателям, отсутствие законодательной базы).

Наиболее удачными примерами беспилотников при работе на открытых пространствах можно считать следующие.

1. Интернет-рилейтер «Amazon» представил первый дрон в 2013 г. Скорость доставки товара беспилотником была в 4 раза быстрее стандартного способа доставки и составляла 30 минут и менее. В 2015 г. компания «Amazon» представила гибридную модель дрона, конструкция которой позволила не только осуществлять перелеты на большие расстояния, но и реализовывать вертикальные взлеты и посадки. Коммерческие доставки стартовали с 2016 г., управление полета беспилотника велось в автоматическом режиме (место приземления обозначалось с помощью QR-кода).

2. Компания «DHL Express» начала первые испытания в 2013 г. Расстояние, которое преодолевал беспилотник «Parcelcopter» для доставки груза, составляло 1 км. 2014 г. транспортировка медикаментов из города 
Норддайх на остров Йюст ${ }^{15} .2016$ г. - скорость перемещения дронов составила 70 км/ч, несмотря на усложненные условия транспортировки (перепад высоты, протяженность маршрута).

Развитие технологий позволяет тестировать разные варианты доставки дронами. По версии многих экспертов, складская логистика - самая перспективная сфера для дронов. Дрон - это транспортное средство, его логично было бы использовать для перемещений грузов. Внутрипроизводственное применение дронов имеет следующую историю.

Технология «FlytWare», используемая в складских помещениях, является специализированным программным обеспечением, которое осуществляет автоматическое считывание штрих-кодов, QR-кодов и предназначается для беспилотных летательных аппаратов. Данная технология применяла автономную навигацию, что позволило отказаться от GPS.

B 2017 г. немецкая компания Linde Material Handling (Linde MH) представила прототип дрона «Flybox» (гексакоптер) для инвентаризационных работ на складах. Важным отличием данной модели была одновременная работа с автономным роботизированным погрузчиком. К сожалению, на складе такая идея выглядит пока слабо реализуемой из-за низкой автономности (не более 20 минут) и необходимости сложного управления множеством устройств. Для этих целей рациональнее использовать роботов-транспортировщиков. Самая реальная область применения дронов - инвентаризация. Важно отметить, что речь идет только про инвентаризацию палет при высотном хранении. Следствие высотного просчета - дополнительное подтверждение свободных мест хранения. Вкупе оба этих процесса - инвентаризация и подтверждение пустых ячеек - позволяют обеспечить дальнейшую беспроблемную работу с пополнениями, размещениями, приемкой запасов. Хотя в настоящее время программное обеспечение может с высокой скоростью считывать с помощью камеры дрона штрихкоды, рассчитывать на полноценный штучный пересчет нельзя.

${ }^{15}$ URL: https://pioneer-doc.readthedocs.io/ru/master/ database/base-module/sphere/sphere.html

\section{Использование дронов \\ в пассажироперевозках}

Компания Uber в 2016 г. опубликовала план проекта Elevate, представляющий из себя концепцию работы сервиса «летающих такси». В 2017 г. прошла первая конференция по городским воздушным перевозкам. В 2019 г. американская компания «Bell Helicopter» представила транспортное средство «Bell Nexus», разработанное по заказу компании Uber. «Bell Nexus» имело гибридную конструкцию с поворотными винтами и использовало два вида источника энергии: бортовые аккумуляторы и газовую турбину. Гибридная, а не чисто электрическая, система движения была выбрана для того, чтобы увеличить грузоподъемность и запас хода аэротакси. Получаемая тяга равномерно распределялась между шестью моторами, приводящими в движение винты, которые обеспечивали вертикальный взлет и посадку, скорость и контроль баланса в полете. Стоит отметить, что возможность вертикального набора высоты в будущем станет жизненно необходимым условием в ограниченном городском пространстве.

В 2020 г. появилась тестовая линия беспилотных аэротакси UberAIR, а в 2023 г. Uber планирует запустить коммерческие полеты.

Компания «Volocopter», первые разработки которой относятся к 2011 г., выпустила двухместный электрический мультикоптер как вариант городского «аэротакси». Официальное разрешение на тестовые полеты было получено только в 2016 г. Двухместное аэротакси VC200 оснащено 18 отдельными электродвигателями (роторами) и могло развивать скорость до 50 км/ч, перемещаясь на расстояние от 25 до 30 км. В 2017 г. компания «Volocopter» представила новую модель пассажирского дрона «Volocopter 2X», максимальная скорость которого составляла около 100 км/ч. В конце августа 2019 г. произведена финальная версия коммерческого аэротакси «Volocity».

Китайская компания «Beijing Yi-Hang Creation Science \& Technology Co» в 2016 г. представила модель пассажирского дрона «EHang 184», а два года спустя - новую модель коптера «EHang 216». Беспилотник способен непрерывно находиться в воздухе до получаса и преодолевать расстояние 
в 35 км, при этом полная зарядка дрона занимает не более двух часов. Аппарат способен подниматься на высоту 500 метров. Тип управления - автономный, с единого центра. Дрон прошел многочисленные испытания в Китае, Австрии и США, совершив более 1000 полетов, в том числе в условиях шторма и плохой видимости, и налетал порядка 7000 часов (2000 из них при участии пилотов).

Высокий уровень современных информационно-коммуникационных технологий позволяет прогнозировать успешное их применение в сфере логистики, однако многие логистические компании по-прежнему не оптимально используют свои ресурсы (средняя загрузка складских мощностей составляет 65-70\%, доля холостых поездок грузового транспорта колеблется от 10 до 15\% и т. д.). Частичное внедрение технологии интернета вещей, унификация протоколов и систем, автоматизация многих технологических процессов на основе их оптимизации для решения задачи минимизации затрат с применением современных информационных технологий - это и есть логистика будущего, т. е. цифровая логистика. Основываясь на проведенном выше анализе основных сфер использования цифровых технологий в логистике, представляется возможным сформулировать стратегические направления ее совершенствования в Республике Беларусь: 1) управление цепями поставок в соответствии c требованиями цифровой экономики и законодательства Республики Беларусь; 2) повышение конкурентоспособности страны за счет развития логистических систем, основанных на современных цифровых технологиях; 3) интеграция в международные логистические системы. Развитие данных направлений позволит сформировать отечественную логистику как открытую и динамично развивающуюся бизнес-систему, создаваемую юридически независимыми предприятиями единого информационного пространства с целью совместного использования своих технологических ресурсов для реализации всех этапов работ по выполнению заказов - от источников пер- вичного сырья до передачи продукции конечному потребителю.

\section{СПИСОК ЛИТЕРАТУРЫ (REFERENCES)}

Антюшеня Д.М. 2016. Транспортно-логистическая система Республики Беларусь: становление и развитие. Минск: БНТУ. 222 с. [Antyushenya D.M. 2016. Transport and logistics system of the Republic of Belarus: formation and development. Minsk: BNTU. 222 p. (In Russ.)]

Батюк Л.И., Гадимова Ф.К. 2015. Логистика в годы Великой Отечественной войны. $A \kappa-$ туальные проблемы гуманитарных и естественных наук. № 10. C. 171-173. [Batyuk L.I., Gadimova F.K. 2015. Logistics during the Great Patriotic War. Aktual'nye problemy gumanitarnykh $i$ estestvennykh nauk. No 10. P. 171-173. (In Russ.)]

Бродецкий Г.Л. 2006. Моделирование логистических систем. Оптимальные решения в условиях риска. Москва: Вершина. 376 с. [Brodetsky G.L. 2006. Modeling of logistics systems. Optimal solutions in the face of risk. Moscow: Vershina. 376 p. (In Russ.)]

Гарнов А.П., Киреева Н.С. 2018. Инструментарий логистики. Москва. ИНФРА-М. 142 с. [Garnov A.P., Kireeva N.S. 2018. Logistics tools. Moscow. INFRA-M. 142 p. (In Russ.)]

Гордон М.П., Карнаухов С.Б. 1998. Логистика товародвижения. Москва: Центр экономики и маркетинга. 168 c. [Gordon M.P., Karnaukhov S.B. 1998. Logistics of goods circulation. Moscow: Tsentr ekonomiki i marketinga. 168 p. (In Russ.)]

Дыбская В.В., Сергеев В.И. 2018. Цифровая логистика и управление цепями поставок: перспективы развития. Логистика: современные тенденции развития. C. 5-11. [Dybskaya V.V., Sergeev V.I. 2018. Digital logistics and supply chain management: development prospects. Logistika: sovremennye tendentsii razvitiya. PP. 5-11. (In Russ.)]

Зверев А.В., Авдей А.Г. 2012. Политическое значение Евразийского таможенного союза для Германии и Европейского Союза. Правовые вопросы Евразийского таможенного союза. Москва: Инфотропик Медиа. С. 13-18. [Zverev A.V., Avdey A.G. 2012. The Political Significance of the Eurasian Customs Union for Germany and the European Union. Pravovye voprosy Evraziyskogo tamozhennogo soyuza. Moscow: Infotropik Media. PP. 13-18. (In Russ.)]

Иванов Д.А. 2006. Логистика: стратегическая кооперация. Москва: Вершина. 176 с. [Ivanov D.A. 2006. Logistics: strategic cooperation. Moscow: Vershina. 176 p. (In Russ.)]

Ковалев М.М., Королева А.А., Дутина А.А. 2017. Транспортная логистика в Беларуси: состояние, перспективы. Минск: Издательский центр 
БГУ. 327 с. [Kovalev M.M., Koroleva A.A., Dutina A.A. 2017. Transport logistics in Belarus: state, prospects. Minsk: Izdatel'skiy tsentr BGU. 327 p. (In Russ.)]

Королева А.А. 2019. Экономические эффекты цифровой логистики. Журнал Белорусского государственного университета. Экономика. № 1. C. 68 -76. [Koroleva A.A. 2019. Economic Effects of Digital Logistics. Zhurnal Belorusskogo gosudarstvennogo universiteta. Ekonomika. No 1. PP. 68-76. (In Russ.)]

Лебедев Ю.Г. 2007. Логистика. Теория гармонизированных иепей поставок. Москва: Издательство МГТУ им. Н.Э. Баумана. 488 с. [Lebedev Yu.G. 2007. Logistics. The theory of harmonized supply chains. Moscow: Izdatel'stvo MGTU im. N.E. Baumana. 488 p. (In Russ.)]

Магомедов А.М. 2014. Транспорт и логистическая интеграция региональной экономики.
Экономика и предпринимательство. № 1-2. C. 231-235. [Magomedov A.M. 2014. Transport and ligistics regional economic integration. Ekonomika $i$ predprinimatel'stoo. No 1-2. PP. 231-235. (In Russ.)]

Родкина T.A., Комарова Е.М. 2017. Информационно-коммуникачионное обеспечение логистики трансграничных перевозок товаров в интегрированном пространстве. Москва: ВИНИТИ РАН. 120 с. [Rodkina T.A., Komarova E.M. 2017. Information and communication support for the logistics of cross-border transportation of goods in an integrated space. Moscow: VINITI RAN. 120 p. (In Russ.)]

Christopher M. 1998. Logistics and Supply Chain Management: Strategies for Reducing Cost and Improving Service. London: Pitman Publishing. PP. 103-104.

Tapscott D. 1996. The Digital Economy: Promise and Peril in the Age of Networked Intelligence. New York: McGraw-Hill. 342 p.

In citation: Belorusskiy Ekonomicheskiy zhurnal. 2021. No 3. PP. 138-149.

Belarusian Economic Journal. 2021. No 3. PP. 138-149.

\section{LOGISTIC INTEGRATION: NEW CONDITIONS AND TECHNOLOGIES}

\section{Svetlana Kuhan ${ }^{1}$}

Author affiliation: ${ }^{1}$ Brest State Technical University (Brest, Belarus).

Corresponding author: Svetlana Kuhan (sfkugan@mail.ru).

ABSTRACT. The article analyzes history logistics development and suggests a stage classification based on the criteria of the functional content and intensity of material flows in different periods. The characteristics of each logistics stage are formulated. The promising areas of logistics development during the digitalization period are reflected.

KEYWORDS: digital logistics, digital technologies, digital transport systems, stages of logistics development.

JEL-code: O10, O30.

DOI: $10.46782 / 1818-4510-2021-3-138-149$

Received 28.04.2021 